\title{
Ventilation-Perfusion Inequality in Chronic Obstructive
}

\section{Pulmonary Disease}

\author{
P. D. Wagner, D. R. Dantzker, R. Dueck, J. L. Clausen, and J. B. West \\ From the Department of Medicine, University of California, San Diego, La Jolla, California 92093
}

\begin{abstract}
A B S T R A C T A multiple inert gas elimination method was used to study the mechanism of impaired gas exchange in 23 patients with advanced chronic obstructive pulmonary disease (COPD). Three patterns of ventilation-perfusion ( $\left.\dot{\mathrm{V}}_{\mathrm{A}} / \dot{Q}\right)$ inequality were found: (a) A pattern with considerable regions of high (greater than 3) $\dot{V}_{A} / \dot{Q}$, none of low (less than 0.1 ) $\dot{V}_{A} / \dot{Q}$, and essentially no shunt. Almost all patients with type A COPD showed this pattern, and it was also seen in some patients with type B. (b) A pattern with large amounts of low but almost none of high $\dot{V}_{\mathrm{A}} / \dot{Q}$, and essentially no shunt. This pattern was found in 4 of 12 type B patients and 1 of type A. (c) A pattern with both low and high $\dot{V}_{A} / Q$ areas was found in the remaining 6 patients. Distributions with high $\dot{V}_{A} / \dot{Q}$ areas occurred mostly in patients with greatly increased compliance and may represent loss of blood-flow due to alveolar wall destruction. Similarly, well-defined modes of low VA/Q areas were seen mostly in patients with severe cough and sputum and may be due to reduced ventilation secondary to mechanical airways obstruction or distortion. There was little change in the $\dot{V}_{A} / Q$ distributions on exercise or on breathing $100 \%$ $\mathrm{O}_{2}$. The observed patterns of $\dot{\mathrm{V}} \mathrm{A} / \mathrm{Q}$ inequality and shunt accounted for all of the hypoxemia at rest and during exercise. There was therefore no evidence for hypoxemia caused by diffusion impairment. Patients with similar arterial blood gases often had dissimilar $\dot{V} A / Q$ patterns. As a consequence the pattern of $\dot{V}_{A} / \dot{Q}$ inequality could not necessarily be inferred from the arterial $\mathrm{PO}_{2}$ and $\mathrm{PCO}_{2}$.
\end{abstract}

\section{INTRODUCTION}

Chronic obstructive pulmonary disease (COPD) is classically associated with abnormalities of pulmonary

Presented in part at the American Thoracic Society Annual Meeting, Cincinnati, Ohio, May 1974. (Am. Rev. Respir. Dis. 109: 706.)

Received for publication 12 January 1976 and in revised form 28 October 976. gas exchange. In the past these abnormalities have most often been characterized by the alveolar-arterial $\mathrm{PO}_{2}$ difference $\left(\mathrm{AaDO}_{2}\right)$, venous admixture (QVA/Q́T), and physiologic deadspace $\left(\dot{V}_{D} / \dot{V}_{T} T\right)$. However, characterization by these indices cannot provide a complete picture of the physiological abnormalities that are present.

An unresolved issue is whether diffusion impairment contributes to the hypoxemia in these patients. It has been known for many years that they may have a low diffusing capacity for carbon monoxide but this measurement is notoriously difficult to interpret in patients with large amounts of uneven ventilation (1). More recently King and Briscoe (2) have argued on the basis of two-compartment models that some of the hypoxemia may be caused by failure of $\mathrm{PO}_{2}$ equilibration between alveolar gas and end-capillary blood.

Consequently there are numerous unanswered questions concerning both the nature of ventilationperfusion $\left(\dot{V}_{\mathrm{A}} / \mathrm{Q}\right)$ inequality and the mechanism of hypoxemia in COPD: $(a)$ the shape, position, and dispersion of the distribution of $\dot{V} A / Q$ ratios remain essentially undefined; $(b)$ to what extent shunting and diffusion impairment are responsible for the hypoxemia are unresolved issues; $(c)$ it is also not known to what degree there is impaired gaseous diffusion in the alveoli and airways as a result of the structural changes in the lungs; $(d)$ the effects of breathing $100 \%$ oxygen are important but poorly understood because of uncertainty about how completely poorly ventilated areas have their nitrogen washed out; (e) the relationships between the pattern of $\dot{V}_{A} / \dot{Q}$ abnormalities, the mechanical properties of the lung, and the clinical picture are not well understood. It

\footnotetext{
${ }^{1}$ Abbreviations used in this paper: $\mathrm{AaDO}_{2}$, alveolar-arterial $\mathrm{PO}_{2}$ difference; BTPS, body temperature, pressure, saturated with water; COPD, chronic obstructive pulmonary disease;

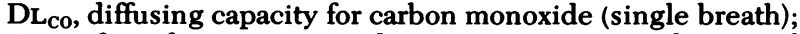
FEV 1 forced expiratory volume in $1 \mathrm{~s}$; FRC, functional residual capacity; $\mathrm{FI}_{\mathrm{O}_{2}}$, fractional concentration, inspired gas; $\dot{V}_{A} / Q$, ventilation-perfusion; VC, vital capacity.
} 
would be of value to know whether the clinical extremes of COPD (as described, for example, by Burrows and co-workers [3]) are in general associated with grossly dissimilar patterns of $\dot{V} A / Q$ inequality, or whether, on the other hand, there is a fundamental similarity in the distribution of $\dot{\mathrm{V}} \mathrm{A} / \dot{\mathrm{Q}}$ ratios across the spectrum of COPD. Resolution of this issue may throw light on the pathophysiology of these clinical entities.

It is the purpose of this paper to attempt to answer, at least in part, the foregoing issues. The primary technique employed in this study is our previously described multiple inert gas elimination method for measuring $\dot{V} \mathrm{~A} / \dot{Q}$ ratio distributions (4-7). In a group of 23 patients with advanced but stable COPD of differing clinical types, the inert gas technique was applied under a variety of conditions, and the results have been related to the standard clinical indices of cardiopulmonary structure and function, including the clinical picture, pulmonary function tests, the chest $\mathrm{X}$-ray, arterial and expired respiratory gas concentrations, and hemodynamic indices of the pulmonary circulation. Particular attention has been applied (Appendix) to the description of variability in distributions compatible with a given data set.

\section{METHODS}

Selection of subjects. 23 male patients with severe and advanced but stable COPD were studied (Table I). Based on clinical and pulmonary function data, the patients were separated into three categories: (a) 8 patients (patients 1-8 in Table I) had the clinical features of COPD type A as defined by Burrows and co-workers (3). In general they had minimal cough or sputum production, marked overdistension of their lungs, no history of peripheral edema, attenuated vessels on the chest X-ray, reduced elastic lung recoil, relatively mild hypoxemia, and no $\mathrm{CO}_{2}$ retention. (b) 12 patients (patients 9-20 in Table I) had the clinical features of COPD type B as defined by Burrows and coworkers. In general these patients had a long history of bronchitis with copious sputum production, evidence of chronic cor pulmonale, normal elastic lung recoil, increased airways resistance, severe hypoxemia, and $\mathrm{CO}_{2}$ retention. (c) 3 patients $(21-23)$ had features common to both the preceding groups.

Preparation of patients. Three catheters were inserted under continuous electrocardiographic monitoring with the patient in the supine position. (a) Using a sterile introducer, a balloon-tipped catheter (Swan-Ganz no. 7 double lumen end hole, Edwards Lab Inc., Santa Ana, Calif.) was inserted percutaneously into an antecubital vein and advanced into the pulmonary artery. Right ventricular, pulmonary artery, and pulmonary artery wedge pressures were recorded at this time; the catheter was then withdrawn slightly for sampling of pulmonary arterial blood away from the wedge position. (b) A Medicut cannula (A. S. Aloe Co., St. Louis, Mo., 20 gauge) was inserted into the radial artery of the nondominant hand. (c) A similar cannula was inserted into the most convenient peripheral arm vein.

The patient was then placed in a comfortable position, generally semirecumbent at an angle of about $30^{\circ}$ to the horizontal. All studies were made in this position.
General outline of experimental protocol. Measurements were obtained under three conditions: breathing air at rest, breathing air during exercise with a pedal ergometer, and breathing $100 \% \mathrm{O}_{2}$ at rest. Not all subjects were able to tolerate exercise, while in others exercise studies could not be made for technical reasons. Thus only 10 of the 23 patients underwent exercise studies (patients 1, 2, 4, 9, 11, 12, 14, 18, 19, and 22; see Table I).

In 17 of the patients the sequence of measurements was (a) breathing air at rest, (b) breathing $100 \% \mathrm{O}_{2}$ at rest, (c) breathing air at rest. In 4 of these patients measurements were made during exercise, breathing air as well. In the remaining 6 patients the sequence of measurements was (a) breathing air at rest, $(b)$ breathing air on exercise, $(c)$ breathing air at rest. In 5 of these patients additional measurements were made during $\mathrm{O}_{2}$ breathing at rest.

Since the details of the preparation of the six gas solutions, methods of infusion and sampling (4), techniques of gas chromatography (6), and the computer analysis $(5,7)$ have all been reported previously, these aspects will not be dealt with here.

The measurements made under any one of the physiological conditions were as follows: with the subject in a general steady state with relatively constant $( \pm 10 \%$ or less $)$ tidal volume and frequency, end tidal $\mathrm{PO}_{2}$ and $\mathrm{PCO}_{2}$, and heart rate, the following samples were taken and measurements made. (a) $10-15 \mathrm{ml}$ heparinized samples of both arterial and pulmonary arterial blood were taken slowly at a uniform rate over approximately $30 \mathrm{~s}$. (b) A simultaneous $20-\mathrm{ml}$ sample (in duplicate) of mixed expired gas was collected. Because of the solubility of halothane, ether, and acetone in plastics and water, special arrangements were necessary for the expired gas collection. The details of the heated flowthrough system for this have been described previously (4). (c) Immediately after the above sampling, heparinized arterial and pulmonary arterial samples $(3 \mathrm{ml})$ were taken for measurement of $\mathrm{PO}_{2}, \mathrm{PCO}_{2}$, and $\mathrm{pH}$ with Radiometer blood gas electrodes (Radiometer Co., Copenhagen, Denmark). Simultaneously, another sample of mixed expired gas was collected for measurement of expired $\mathrm{PO}_{2}$ and $\mathrm{PCO}_{2}$. (d) Minute ventilation was recorded minute by minute using a calibrated Wright's respirometer (British Oxygen Co., Essex, England). (e)Cardiac output was measured by dye dilution using indocyanine green and a Gilford densitometer (Gilford Instrument Laboratories, Inc., Oberlin, Oh.). (f) End tidal $\mathrm{Po}_{2}$ and $\mathrm{PCO}_{2}$ and mixed expired $\mathrm{PO}_{2}$ and $\mathrm{PCO}_{2}$ were recorded continuously by mass spectrometer (Perkin-Elmer Corp., Pomona, Calif.).

A single 10-ml heparinized sample of venous blood was collected once during the study for measurement of the $P_{50}$ of the oxyhemoglobin dissociation curve. This measurement was made by tonometering the sample of blood at least three different $\mathrm{PO}_{2}$ values in the range $20-35 \mathrm{mmHg}$, and measuring both the $\mathrm{PO}_{2}$ and saturation of the sample using the Instrumentation Laboratory (Lexington, Mass.) cooximeter and blood gas electrode system.

Calculations. Having obtained the $\dot{V}_{A} / Q$ ratio distribution by computer analysis of the inert gas data (the value of the smoothing coefficient $\mathrm{Z}$ was 40 ), it was possible to compute respiratory gas exchange compatible with each recovered distribution by means of a computer program (8). Knowing the directly measured value for mixed venous and inspired $\mathrm{PO}_{2}$ and $\mathrm{PCO}_{2}$, acid-base status, hemoglobin and hematocrit, $\mathrm{P}_{50}$, and body temperature, this program was used to construct a $\bigvee_{A} / Q$ line on the $\mathrm{O}_{2}-\mathrm{CO}_{2}$ diagram. On the assumption of complete alveolar end-capillary partial pressure equilibrium for oxygen and carbon dioxide, and taking into account the small amount of nitrogen exchange that occurs in 
TABLE I

Anthropometric and Pulmonary Function Data

\begin{tabular}{|c|c|c|c|c|c|c|c|c|c|c|c|c|c|c|c|c|c|}
\hline \multirow{2}{*}{$\begin{array}{l}\mathrm{Pa}- \\
\text { tient }\end{array}$} & \multirow[b]{2}{*}{ Age } & \multirow[b]{2}{*}{ Weight } & \multirow[b]{2}{*}{ Height } & \multirow{2}{*}{$\begin{array}{l}\text { Sur- } \\
\text { face } \\
\text { area }\end{array}$} & \multirow[b]{2}{*}{ Sputum } & \multicolumn{5}{|c|}{ Lung volumes, liters BTPS } & \multirow[b]{2}{*}{$\mathrm{FEV}_{1}$} & \multirow[b]{2}{*}{ MMEFR } & \multirow[b]{2}{*}{ Raw } & \multirow[b]{2}{*}{$\mathrm{CL}_{\mathrm{L}}$} & \multirow{2}{*}{$\begin{array}{c}\mathrm{P}_{\mathrm{TP}} \\
\text { at } \\
\mathrm{TLC}\end{array}$} & \multirow{2}{*}{$\begin{array}{l}\mathrm{DL}_{\mathrm{co}} \\
\text { pre- } \\
\text { dicted }\end{array}$} & \multirow{2}{*}{$\begin{array}{c}\text { Mean } \\
\text { pul- } \\
\text { monary } \\
\text { arterial } \\
\text { pressure }\end{array}$} \\
\hline & & & & & & TLC & FRC & $\mathrm{RV}$ & vC & FVC & & & & & & & \\
\hline & $y r$ & $k g$ & $\mathrm{~cm}$ & $m^{2}$ & & \multicolumn{5}{|c|}{ liters $B T P S$} & $\%$ & liter/s & $\begin{array}{c}\mathrm{cm} \\
\mathrm{H}_{2} \mathrm{O} / \\
\text { liter/s }\end{array}$ & $\begin{array}{c}\text { literl } \\
c m \\
\mathrm{H}_{2} \mathrm{O}\end{array}$ & $\begin{array}{c}\mathrm{cm} \\
\mathrm{H}_{2} \mathrm{O}\end{array}$ & $\%$ & $m m \mathrm{Hg}$ \\
\hline 1 & 62 & 96.8 & 185 & 2.20 & Minimal & 8.8 & 6.6 & 5.4 & 3.4 & 2.3 & 37 & 0.2 & 4.0 & 0.140 & 9.9 & 100 & 14 \\
\hline 2 & 64 & 64.5 & 170 & 1.75 & Minimal & 8.4 & 7.2 & 6.2 & 2.2 & 1.0 & 39 & 0.1 & 3.2 & 0.170 & 7.5 & 44 & 12 \\
\hline 3 & 60 & 71.8 & 168 & 1.81 & Minimal & 7.3 & 5.6 & 4.1 & 3.2 & 2.6 & 33 & 0.2 & 2.2 & 0.199 & 9.4 & 157 & 13 \\
\hline 4 & 46 & 52.0 & 163 & 1.58 & Moderate & 8.1 & 5.9 & 4.5 & 3.6 & 2.8 & 43 & 0.4 & 2.4 & - & - & 38 & 15 \\
\hline 5 & 65 & 59.0 & 170 & 1.68 & Minimal & 7.1 & 5.1 & 3.9 & 3.2 & 2.7 & 44 & 0.3 & 2.1 & 0.132 & 11.7 & 24 & 9 \\
\hline 6 & 54 & 61.0 & 168 & 1.69 & Minimal & 5.4 & 4.0 & 3.4 & 2.0 & 1.8 & 50 & 0.3 & 2.3 & 0.190 & 11.3 & 89 & 11 \\
\hline 7 & 76 & 72.7 & 173 & 1.86 & Minimal & 6.7 & 4.6 & 3.4 & 3.3 & 2.7 & 42 & 0.4 & 1.6 & 0.242 & 9.6 & - & 15 \\
\hline 8 & 73 & 73.6 & 180 & 1.92 & Minimal & 9.9 & 7.9 & 7.3 & 2.6 & 2.4 & 30 & 0.2 & 2.1 & 0.128 & 9.1 & 62 & 12 \\
\hline 9 & 64 & 68.6 & 168 & 1.75 & Severe & 5.2 & 4.3 & 3.5 & 1.7 & 1.5 & 39 & - & 3.3 & - & - & - & 25 \\
\hline 10 & 76 & 72.3 & 168 & 1.82 & Severe & 7.7 & 6.4 & 5.2 & 2.5 & 2.3 & 22 & 0.2 & 5.5 & 0.067 & 19.2 & 96 & 12 \\
\hline 11 & 55 & 93.2 & 188 & 2.20 & Moderate & 5.1 & 3.7 & 2.6 & 2.5 & 2.4 & 48 & 0.3 & 5.3 & - & - & 78 & 33 \\
\hline 12 & 49 & 77.7 & 180 & 1.97 & Moderate & 9.3 & 8.2 & 7.4 & 1.9 & 1.9 & 29 & 0.2 & 10.8 & 0.348 & 5.7 & 17 & 15 \\
\hline 13 & 48 & 63.2 & 178 & 1.79 & Severe & 8.9 & 7.5 & 7.1 & 1.8 & 1.5 & 44 & 0.2 & 3.7 & 0.130 & 13.8 & 86 & 20 \\
\hline 14 & 53 & 85.5 & 178 & 2.03 & Moderate & 6.5 & 3.8 & 3.4 & 3.1 & 3.0 & 59 & 2.2 & 3.1 & - & - & 119 & 24 \\
\hline 15 & 47 & 80.9 & 173 & 1.94 & Moderate & 8.1 & 6.4 & 5.7 & 2.4 & 1.7 & 33 & 0.2 & 4.0 & 0.038 & 15.8 & 50 & 31 \\
\hline 16 & 53 & 71.4 & 163 & 1.77 & Severe & 7.4 & 6.7 & 5.9 & 1.5 & 1.4 & 47 & 0.2 & 5.9 & 0.067 & 13.7 & 116 & 40 \\
\hline 17 & 55 & 84.0 & 185 & 2.08 & Moderate & 11.3 & 9.6 & 8.5 & 2.8 & 2.0 & 42 & 0.2 & 5.0 & 0.096 & 18.9 & 96 & 10 \\
\hline 18 & 44 & 100.0 & 180 & 2.19 & Severe & 6.1 & 4.1 & 3.4 & 2.7 & 2.6 & 58 & 0.7 & - & - & - & 105 & 25 \\
\hline 19 & 60 & 105.0 & 175 & 2.20 & Moderate & 6.7 & 3.0 & 2.0 & 4.7 & 4.5 & 58 & 0.9 & 1.3 & 0.248 & 27.9 & 52 & 32 \\
\hline 20 & 66 & 72.7 & 180 & 1.91 & Moderate & 8.6 & 7.0 & 6.3 & 2.3 & 1.8 & 33 & 0.1 & 3.2 & 0.270 & 12.3 & - & 40 \\
\hline 21 & 67 & 52.3 & 173 & 1.62 & Moderate & 7.2 & 5.8 & 5.2 & 2.0 & 1.3 & 33 & 0.1 & 5.0 & 0.167 & 7.4 & - & 25 \\
\hline 22 & 53 & 59.0 & 193 & 1.84 & Severe & 9.3 & 8.0 & 6.9 & 2.4 & 2.2 & 19 & 0.1 & - & 0.410 & 3.3 & 37 & 26 \\
\hline 23 & 60 & 65.0 & 185 & 1.88 & Moderate & 8.2 & 6.6 & 4.7 & 3.5 & 3.5 & 48 & 0.4 & - & - & - & - & 21 \\
\hline
\end{tabular}

TLC, total lung capacity; FRC, functional residual capacity; RV, residual volume; VC, vital capacity; FVC, forced vital capacity; FEV , forced expiratory volume in 1 s; MMEFR, maximal mid-expiratory flow rate; Raw, airways resistance; $\mathrm{CL}$, compliance of lung and chest wall; PTP, transpulmonary pressure.

each gas exchange unit, end-capillary and alveolar values for $\mathrm{O}_{2}$ and $\mathrm{CO}_{2}$ were calculated for each $\dot{V}_{A} / Q$ compartment in the distribution. The mixed arterial and mixed expired $\mathrm{PO}_{2}$ and $\mathrm{PCO}_{2}$ values could then be computed by the ventilation and perfusion-weighted sums of the compartmental alveolar and end-capillary values, respectively. These calculated values could then be compared with directly measured mixed expired and arterial $\mathrm{PO}_{2}$ and $\mathrm{PCO}_{2}$.

\section{RESULTS}

\section{Retention-solubility and excretion-solubility curves and distribution of $\dot{V} A / Q \dot{Q}$ ratios at rest}

Each of the 23 patients was found to have one of three distinct patterns, which are illustrated in Fig. 1. In the example of each pattern, retention (ratio of arterial to mixed venous partial pressure) and excretion (ratio of mixed expired to mixed venous partial pressure) are plotted against inert gas solubility for the six gases used. In addition, the corresponding curves for a homogeneous lung with the measured total ventilation and blood flow are included as solid lines for comparison. From the retention and excretion values in Fig. 1A, it is evident that there are large differences in the raw data among the three patterns.
These differences involve both shape and position of the retention and excretion curves. Thus in the upper panel, retention is not very different in shape from that of the homogeneous lung, but is shifted leftward of the homogeneous curve. By contrast the excretion curve falls away from the homogeneous curve mainly for the gases halothane and ether so that the shape differs from that of the homogeneous lung (this is better illustrated in the lower panel). By contrast with the upper panel, the middle panel demonstrates that ethane and cyclopropane retentions differ greatly from the homogeneous lung, and the two retention curves thus have different shapes. The excretion curve has essentially the same shape as the homogeneous lung but is shifted to the right. In the lowest panel, the excretion curve type of the upper panel and retention curve type of the middle panel coexist. Retention and excretion values of all 23 subjects are given in the Appendix. ${ }^{2}$

\footnotetext{
${ }^{2}$ Supplemental material, Figs. 8-10, Tables III-V, and an Appendix, has been deposited with the National Auxiliary Publications Service (NAPS) as NAPS document no. 02929. This information may be ordered from ASIS/NAPS, $\%$ Microfiche Publications, 305 East 46th Street, New York 10017. Remit with order for each NAPS document number
} 

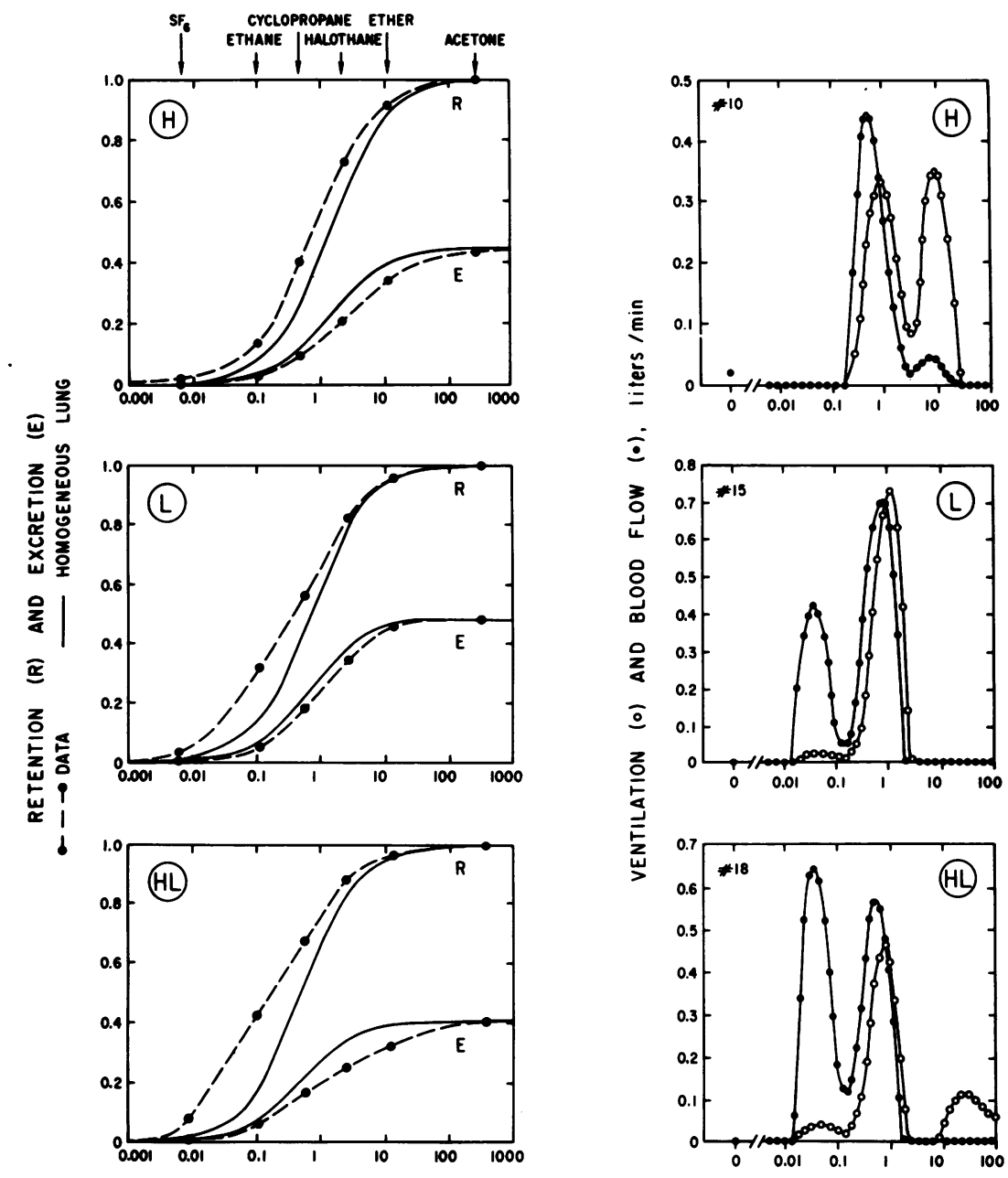

BLOOD-GAS PARTITION COEFFICIENT

A

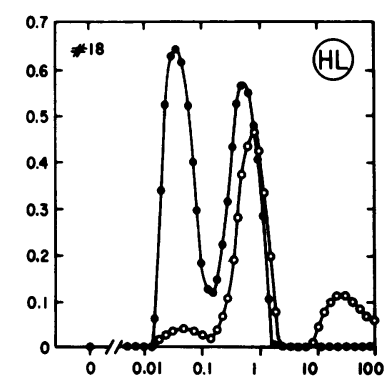

VENTILATION-PERFUSION RATIO

B

FIGURE 1 The three stereotypes of $\dot{V} A / Q$ inequality and the retention and excretion values corresponding to each. The upper panel $(H)$ shows areas of normal and high $\dot{V} A / Q$ without areas of low $\dot{V}_{A} / \dot{Q}$ and essentially no shunt. Retention values $(R)$ lie on a line almost parallel to the homogeneous relationships but shifted to the left, while the excretion curve $(E)$ has a shape different from that of the homogeneous relationship (better shown in the bottom panel). The middle example $(L)$ is the mirror image of the upper panel both with respect to the $\dot{V} / Q$ pattern (low but not high $V_{A} / Q$ areas) and the retention and excretion curves. The lower panel $(H L)$ combines the features of each of the preceding examples, both with respect to the VA/Q pattern and the retention and excretion curves. Note the large absolute differences in retention and excretion (for gases of medium solubility) among the three examples.

Fig. 1B shows that three distinct patterns of $\dot{V} A / Q$ distribution as derived from the retention-solubility and excretion-solubility curves could be identified. (a) Type $\mathrm{H}$ (high) pattern was so named because it is characterized by a mode of high $\dot{V}_{A} / Q$ units to the

$\$ 1.50$ for microfiche or $\$ 5.00$ for photocopies for up to 30 pages; for each additional page over the first 30 pages, there is a 15 charge per page. Checks should be made payable to Microfiche Publications. right of the main body of the distribution. This mode contains little blood flow so the $H$ pattern has almost all of its blood flow in the region of lower $\dot{V} A / Q$. This last point is the most satisfactory identifying feature. (b) By contrast type L (low) pattern is characterized by a mode of low $\dot{V} A / \dot{Q}$ units and has most of its ventilation in the region of higher $\dot{V} A / Q$. (c) Type HL (high, low) has additional modes both above and below the main body. Position along the $\dot{V}_{A} / Q$ scale is not per se considered to be a criterion for classification. 

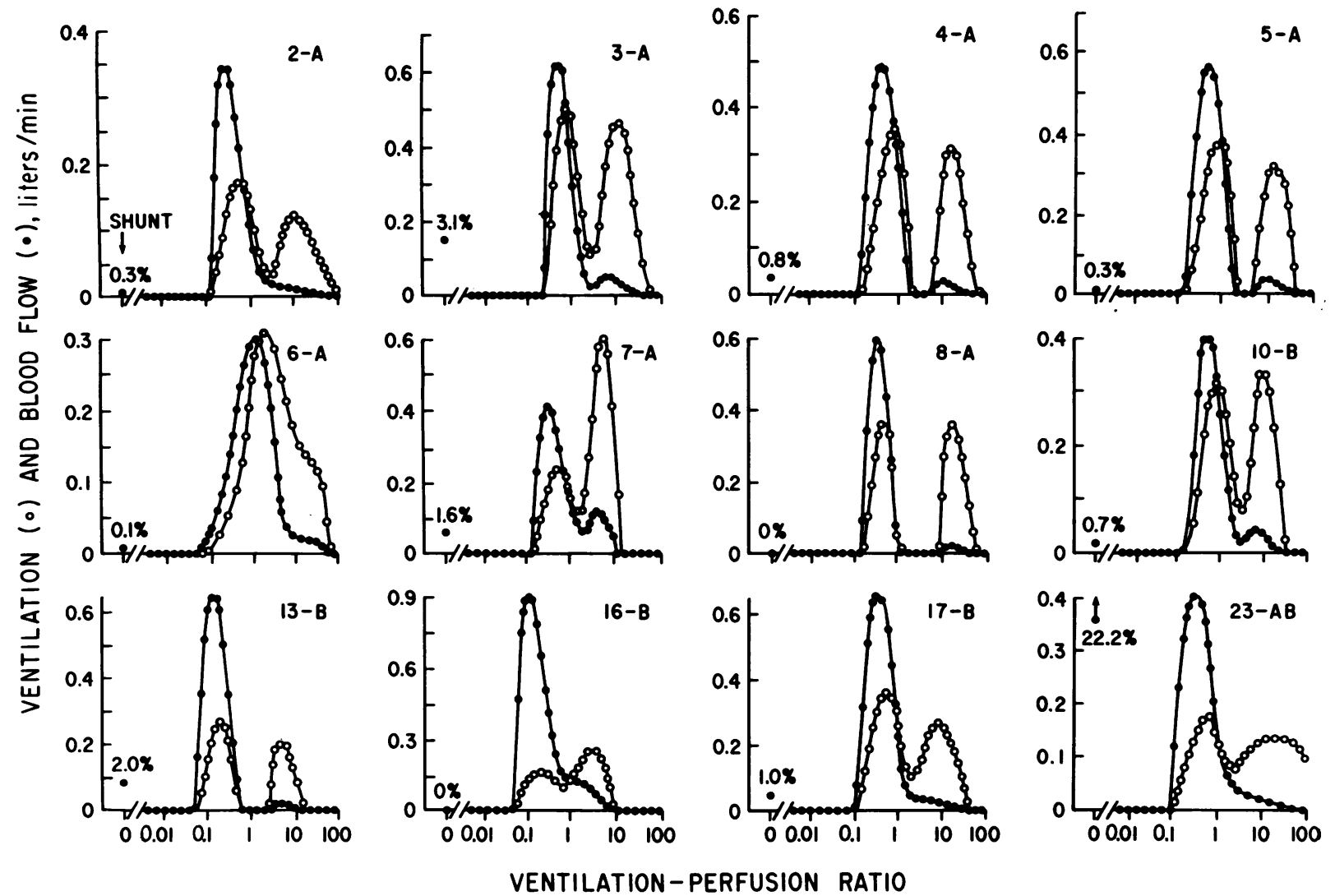

FIGURE $2 \mathrm{H}$ pattern. This was found in 12 of the 23 subjects. Note the basic similarity of the distribution pattern in all patients: areas of normal and high VA/Q but little or no shunt (except case 23) and no areas of very low VA/Q. Patients 2-8 had clinical features of type A COPD and patients 10-17 features predominantly of type B COPD. Patient 23 showed features of both and was the only patient in this group with a large shunt.

Thus patients 16B and 19B (Figs. 2 and 3) have all of the ventilation and blood flow in the same region, but the patterns are different.

All patients had base-line (resting) distributions measured twice during the study at least $1 \mathrm{~h}$ apart, and each time in duplicate. In every case, the pattern $(\mathrm{H}, \mathrm{L}$, or $\mathrm{HL})$ remained unchanged throughout these four measurements, indicating its reproducibility.

Comparing the retention-solubility and excretionsolubility curves with the resulting distributions, it is evident therefore that high $\dot{\mathrm{V}} \mathrm{A} / \dot{Q}$ areas (patterns $\mathrm{H}$ and HL) are mainly evidenced by a fall in excretion of the soluble gases halothane and ether, while in a similar manner low $\dot{V}_{\mathrm{A}} / \dot{Q}$ areas reflect an increase in retention of the less soluble gases. The necessary relationships between the patterns of $\dot{V}_{A} / Q$ inequality and the shapes of the retention-solubility and excretion-solubility curves have been examined in detail elsewhere (9).

It should be noted at this point that the distribution recovered in each case is not the only one compatible with the data within the limits of experimental error. For this reason considerable effort was made to define the possible differences that could exist within the family of compatible distributions in each case. In the Appendix, ${ }^{2}$ using retentions from patients 1,4 , and 9, we show that the three patterns shown in Fig. 1 cannot be confused with one another on the basis of nonuniqueness of the method.

The distributions recovered in all 23 patients appear in Figs. 2, 3, and 4. Here, patients were grouped according to the $\dot{V} A / Q$ pattern $(H, L$, or $H L)$, and the similar pattern classes are evident. The fundamental physiologic defect common to the 23 patients is severe irreversible airways obstruction so that the immediate question is whether there is an explanation for the widely differing classes of $\dot{V} A / Q$ patterns. Consequently, the pattern in each case was examined in relation to the available clinical and physiological data (Tables I and II).

The relationships between the $\dot{V} A / Q$ pattern and the clinical classification (predominantly type $\mathrm{A}$, predominantly type $\mathrm{B}$, or mixed) is shown in Fig. 5 . Seven of the eight patients classified as type $A$ had showed a distribution of pattern $\mathrm{H}$; only one had 


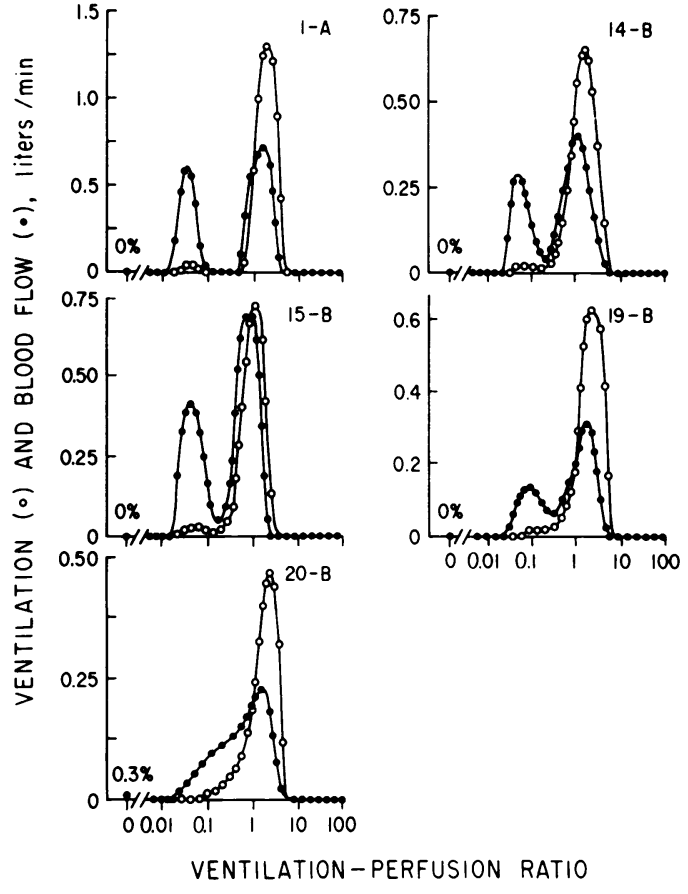

FIgURE 3 L pattern. This was found in 5 of the 23 subjects. Note the areas of low $\dot{V}_{A} / Q$ but essentially no shunt and no areas of very high $\dot{V}_{A} / \dot{Q}$ (cf. Fig. 2). Patient 1 had features of type A COPD while patients 14-20 had features of type B COPD.

pattern L. By contrast, the $\dot{V} A / Q$ patterns in patients classified as type B were diverse: one-third had low but not high $\dot{V}_{A} / Q \dot{Q}$ areas (pattern L); one-third had high but not low $\dot{\mathrm{V}}_{\mathrm{A}} / \dot{\mathrm{Q}}$ areas (pattern $\mathrm{H}$ ); and one-third had both (pattern HL). Of the three patients who had clear clinical features of mixed types A and B COPD, two had both high and low $\dot{V}_{A} / \dot{Q}$ areas (pattern HL), and one had the high $\dot{V}_{A} / \dot{Q}$ pattern $(H)$.

Thus it can be seen from Fig. 5 that 10 of the 11 patients who had clinical evidence of type A COPD (with or without associated signs of type B COPD) had $\dot{V} \mathrm{~A} / \dot{Q}$ distributions containing high $\dot{V}_{A} / \dot{Q}$ modes. Of the 15 patients who had clinical features of type B COPD (with or without associated signs of type A COPD), 10 showed distributions containing low Vं $\mathrm{A} / \dot{Q}$ areas (patterns L or HL) but 5 did not. Of the 12 type B patients without clinical evidence of type A COPD, 8 did in fact have areas of high $\dot{V}_{A} / \dot{Q}$, although 3 had abnormally increased static compliance (Table I, patients 12,19, and 20) and in 4 others compliance measurements were not made.

These results therefore suggest that patients with advanced COPD of the type A variety are very likely to have high $\dot{V} A / \dot{Q}$ areas. Furthermore, these patients are unlikely to have distinct low $\dot{V}_{A} / \dot{Q}$ areas unless they have clinical evidence of type B COPD as well. On the other hand, those patients thought to be of the type $B$ variety commonly have distinct low and/or high $\dot{\mathrm{V}} \mathrm{A} / \mathrm{Q}$ areas although there is clearly much more variability within this group. The possible relationships between individual pulmonary function data and the $\dot{V}_{\mathrm{A}} / \dot{Q}$ pattern are discussed later.

\section{Shunt}

Only 2 of the 23 patients had shunts greater than $5 \%$ of the cardiac output while breathing air. The mean shunt in these 21 patients was $0.7 \%$ of the cardiac output with a range of $0.0-4.4$. The remaining two (patients 11 [type B] and 23 [mixed type A and B], respectively, had shunts of 12.4 and $22.2 \%$ breathing air. Neither of these patients had clinical evidence of a right to left intracardiac shunt, nor chest X-ray evidence of areas of atelectasis or infiltration so that the site of shunting was not evident. Upon breathing $100 \% \mathrm{O}_{2}$ for $30 \mathrm{~min}$, shunts indicated by the inert gas method generally increased but only by small amounts. The mean shunt in the group of 21 breathing $100 \% \mathrm{O}_{2}$ was $1.6 \%$ of cardiac output with a range of 0.0-7.2. In the remaining two patients, the shunts measured by the method during $\mathrm{O}_{2}$ breathing were 13.9 and $20.4 \%$, respectively. The mean increase in percent shunt for all 23 patients following $\mathrm{O}_{2}$ breathing was 0.8 .

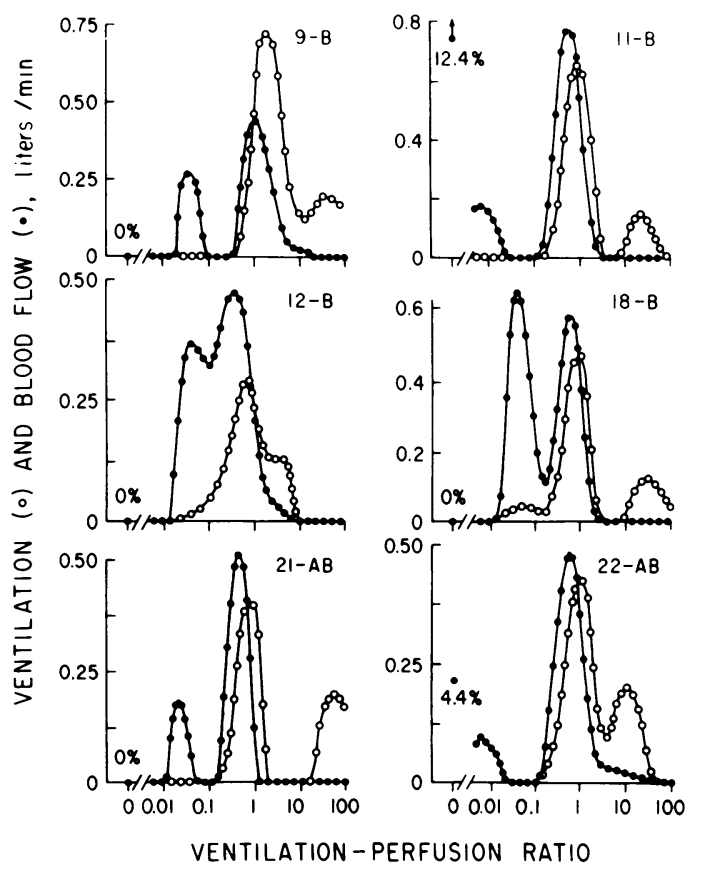

Figure $4 \mathrm{HL}$ pattern found in 6 of the 23 subjects. Both low and high $\dot{V}_{A} / Q$ areas are present and in two, sizable shunts are demonstrated as well. Patients 9-18 had features of type B COPD, and patients 21-22 had features of both types A and B COPD. 
TABLE II

Gas Exchange Data

\begin{tabular}{|c|c|c|c|c|c|c|c|c|c|c|c|c|c|c|c|c|c|c|}
\hline \multirow[b]{2}{*}{$\begin{array}{c}\mathrm{Pa}- \\
\text { tient }\end{array}$} & \multirow{2}{*}{$\begin{array}{l}\text { Pre- } \\
\text { dom- } \\
\text { inant } \\
\text { clin- } \\
\text { ical } \\
\text { type }\end{array}$} & \multirow{2}{*}{$\begin{array}{c}\dot{\mathrm{V}}_{\mathrm{A}} / \mathrm{Q} \\
\text { dis- } \\
\text { tribu- } \\
\text { tion } \\
\text { pat- } \\
\text { tern }\end{array}$} & \multirow{2}{*}{$\begin{array}{l}\text { Min- } \\
\text { ute } \\
\text { venti- } \\
\text { lation }\end{array}$} & \multirow{2}{*}{$\begin{array}{l}\text { Respi- } \\
\text { ratory } \\
\text { fre- } \\
\text { quency }\end{array}$} & \multirow{2}{*}{$\begin{array}{l}\text { Tidal } \\
\text { vol- } \\
\text { ume }\end{array}$} & \multirow{2}{*}{$\begin{array}{l}\text { Car- } \\
\text { diac } \\
\text { out- } \\
\text { put }\end{array}$} & \multirow{2}{*}{$\begin{array}{l}\text { Ve- } \\
\text { nous } \\
\text { ad- } \\
\text { mix- } \\
\text { ture }\end{array}$} & \multirow[b]{2}{*}{ Shunt } & \multirow{2}{*}{$\begin{array}{l}\text { Phys- } \\
\text { iolog- } \\
\text { ical } \\
\text { dead- } \\
\text { space }\end{array}$} & \multirow{2}{*}{$\begin{array}{l}\text { Ven- } \\
\text { tila- } \\
\text { tion } \\
\text { to un- } \\
\text { per- } \\
\text { fused } \\
\text { lung }\end{array}$} & \multicolumn{2}{|c|}{ Arterial $\mathrm{Po}_{2}$} & \multicolumn{2}{|c|}{ Arterial $\mathrm{PCO}_{2}$} & \multicolumn{2}{|c|}{$\begin{array}{l}\text { Blood flow } \\
\text { distribution }\end{array}$} & \multicolumn{2}{|c|}{$\begin{array}{l}\text { Ventilation } \\
\text { distribution }\end{array}$} \\
\hline & & & & & & & & & & & $\begin{array}{l}\text { Meas- } \\
\text { ured }\end{array}$ & $\begin{array}{c}\text { Pre- } \\
\text { dicted }\end{array}$ & $\begin{array}{l}\text { Meas- } \\
\text { ured }\end{array}$ & $\begin{array}{c}\text { Pre- } \\
\text { dicted }\end{array}$ & $\begin{array}{l}\text { Mean } \\
\dot{V} A / Q\end{array}$ & $\begin{array}{l}\log _{e} \\
\text { SD }\end{array}$ & $\begin{array}{l}\text { Mean } \\
\dot{V}_{A} / Q\end{array}$ & $\begin{array}{c}\log _{e} \\
\text { SD }\end{array}$ \\
\hline & & & $\begin{array}{l}\text { liters/ } \\
\min \end{array}$ & $\min ^{-1}$ & $\begin{array}{c}m l \\
B T P S\end{array}$ & $\begin{array}{l}\text { liters/ } \\
\min \end{array}$ & $\%$ & $\%$ & $\%$ & $\%$ & & & & & & & & \\
\hline 1 & $\mathbf{A}$ & $\mathbf{L}$ & 12.1 & 13.5 & 900 & 6.8 & 28.7 & 0.0 & 31.8 & 29.5 & 71 & 66 & 25 & 26 & 0.39 & 1.61 & 1.63 & 0.66 \\
\hline 2 & A & $\mathbf{H}$ & 6.5 & 16.0 & 410 & 3.4 & 8.2 & 0.3 & 51.3 & 41.6 & 67 & 76 & 54 & 54 & 0.55 & 0.90 & 3.05 & 1.51 \\
\hline 3 & A & $\mathbf{H}$ & 11.0 & 14.0 & 790 & 4.4 & 10.9 & 3.1 & 38.2 & 21.8 & 63 & 69 & 34 & 34 & 0.93 & 0.88 & 4.22 & 1.42 \\
\hline 4 & A & $\mathrm{H}$ & 11.8 & 24.0 & 490 & 4.1 & 18.5 & 0.8 & 55.8 & 41.7 & 66 & 58 & 39 & 39 & 0.66 & 0.76 & 3.28 & 1.69 \\
\hline 5 & $\mathbf{A}$ & $\mathrm{H}$ & 10.5 & 15.0 & 700 & 3.5 & 12.9 & 0.3 & 49.7 & 42.5 & 65 & 67 & 40 & 40 & 0.81 & 0.87 & 2.84 & 1.26 \\
\hline 6 & $\mathbf{A}$ & $\mathbf{H}$ & 8.8 & 17.0 & 520 & 4.1 & 18.4 & 0.1 & 54.3 & 39.1 & 67 & 71 & 41 & 42 & 1.10 & 0.95 & 2.67 & 0.95 \\
\hline 7 & A & $\mathrm{H}$ & 11.9 & 17.0 & 700 & 3.2 & 22.1 & 1.6 & 47.2 & 36.0 & 55 & 56 & 34 & 33 & 0.92 & 1.05 & 3.34 & 1.07 \\
\hline 8 & A & $\mathbf{H}$ & 8.6 & 13.0 & 660 & 4.1 & 16.0 & 0.0 & 45.0 & 32.2 & 58 & 60 & 45 & 46 & 0.68 & 0.66 & 2.88 & 1.70 \\
\hline 9 & B & $\mathrm{HL}$ & 16.1 & 28.0 & 580 & 4.2 & 21.3 & 0.0 & 50.6 & 41.3 & 69 & 64 & 46 & 45 & 0.73 & 1.53 & 3.21 & 1.23 \\
\hline 10 & B & $\mathbf{H}$ & 10.5 & 20.5 & 510 & 4.0 & 13.0 & 0.7 & 44.9 & 34.1 & 68 & 68 & 39 & 37 & 0.80 & 0.76 & 1.92 & 1.19 \\
\hline 11 & B & HL & 11.9 & 23.0 & 520 & 8.3 & 42.2 & 12.4 & 45.3 & 34.0 & 44 & 44 & 52 & 53 & 0.40 & 1.24 & 1.69 & 1.34 \\
\hline 12 & B & HL & 8.7 & 16.0 & 540 & 7.4 & 39.6 & 0.0 & 43.3 & 35.9 & 56 & 49 & 47 & 47 & 0.32 & 1.08 & 1.00 & 0.93 \\
\hline 13 & B & $\mathrm{H}$ & 7.0 & 18.5 & 380 & 4.4 & 39.5 & 2.0 & 40.8 & 32.7 & 46 & 47 & 58 & 60 & 0.41 & 0.77 & 2.05 & 1.66 \\
\hline 14 & B & L & 10.6 & 19.0 & 560 & 7.3 & 36.4 & 0.0 & 36.2 & 35.3 & 55 & 50 & 39 & 39 & 0.30 & 1.64 & 1.27 & 0.78 \\
\hline 15 & B & $\mathbf{L}$ & 12.3 & 20.5 & 600 & 5.8 & 36.3 & 0.0 & 42.8 & 38.9 & 47 & 48 & 50 & 51 & 0.47 & 1.43 & 1.61 & 0.74 \\
\hline 16 & B & $\mathbf{H}$ & 8.1 & 23.0 & 350 & 5.9 & 53.2 & 0.0 & 45.9 & 34.5 & 38 & 39 & 64 & 65 & 0.26 & 1.08 & 1.04 & 1.33 \\
\hline 17 & B & $\mathbf{H}$ & 9.9 & 10.5 & 940 & 5.2 & 13.0 & 1.0 & 44.7 & 27.7 & 67 & 62 & 38 & 36 & 0.70 & 0.85 & 2.94 & 1.45 \\
\hline 18 & B & HL & 10.0 & 22 & 450 & 7.9 & 48.8 & 0.0 & 41.0 & 35.7 & 41 & 43 & 52 & 53 & 0.21 & 1.46 & 1.51 & 1.55 \\
\hline 19 & B & $\mathbf{L}$ & 10.8 & 12 & 900 & 4.7 & 22.1 & 0.0 & 39.1 & 34.2 & 64 & 57 & 36 & 38 & 0.75 & 1.27 & 1.81 & 0.68 \\
\hline 20 & B & $\mathbf{L}$ & 10.2 & 27 & 380 & 2.7 & 19.3 & 0.3 & 43.8 & 42.0 & 54 & 54 & 40 & 40 & 0.98 & 1.05 & 2.55 & 1.00 \\
\hline 21 & Mixed & HL & 8.2 & 24 & 340 & 4.7 & 30.0 & 0.0 & 52.0 & 35.5 & 52 & 52 & 62 & 59 & 0.31 & 1.40 & 2.02 & 1.53 \\
\hline 22 & Mixed & HL & 8.2 & 14 & 590 & 4.1 & 27.9 & 4.4 & 56.7 & 31.1 & 50 & 55 & 47 & 48 & 0.50 & 1.51 & 3.60 & 1.63 \\
\hline 23 & Mixed & $\mathbf{H}$ & 10.2 & 22 & 460 & 5.6 & 33.3 & 22.2 & 56.0 & 43.3 & 69 & 64 & 57 & 57 & 0.40 & 0.94 & 3.50 & 1.90 \\
\hline
\end{tabular}

Thus, most of the patients had little or no intrapulmonary shunting, and while there was a small increase in shunt after breathing $100 \% \mathrm{O}_{2}$, this was of minor proportions, even in those patients having considerable amounts of lung with low $\dot{V}_{A} / \dot{Q}$ ratios (i.e., those patterns $\mathrm{L}$ or HL) in whom lung units with $\dot{\mathrm{V}} \mathrm{A} / \dot{Q}$ ratios considerably below critical values (10) were present. By contrast, in a group of patients with post-traumatic respiratory failure who also had low $\dot{V} \mathrm{~A} / \dot{Q}$ areas of lung (11), there was a considerably greater increase in shunt given by the inert gas method upon breathing $100 \% \mathrm{O}_{2}$. Possible reasons for the lack of development of larger shunts while breathing $\mathrm{O}_{2}$ are discussed later.

\section{Deadspace}

In the inert gas method, the proportion of ventilation that is contained in the compartment of infinitely high $\dot{V} A / \dot{Q}$ (deadspace) comes from several sources: instrumental deadspace, anatomic deadspace, gas exchange units that are unperfused, perfused gas exchange units with $\dot{V}_{A} / \dot{Q}$ ratios $>100$. Instrumental deadspace is accountable, but the remainder cannot be separately identified.
In a study of 12 normal volunteers of ages 21-60 (4), the value of deadspace as defined above and expressed in milliliters was very close to the body weight in pounds (mean of $0.43 \mathrm{ml}$ body temperature, pressure, saturated with water (BTPS)/kg body weight). None of these subjects was either cachectic or grossly obese, or had an abnormal functional residual capacity (FRC).

The 11 patients with type A COPD (including the 3 with mixed type A and B diseases) had a mean weight of $66 \mathrm{~kg}$ and height of $1.73 \mathrm{~m}$, while those with type B disease had a mean weight of $81.4 \mathrm{~kg}$ and height of $1.75 \mathrm{~m}$. Mean total deadspace after subtracting the instrumental component in the first group was $217 \mathrm{ml} \mathrm{BTPS} / \mathrm{breath}(0.68 \mathrm{ml} / \mathrm{kg})$ while in the second group it was $201 \mathrm{ml} \mathrm{BTPS} / \mathrm{breath}(0.51 \mathrm{ml} / \mathrm{kg})$.

Much if not all of this increase can probably be accounted for by the effect of increased FRC (Table I) on airway caliber, and it is not possible to ascertain whether any of the increased deadspace is attributable to ventilation of unperfused peripheral gas exchange units in the lung. Certainly rough extrapolation of the regression equation of Hart et al. (12) to an FRC of $169 \%$ of predicted (mean of all patients in the present 

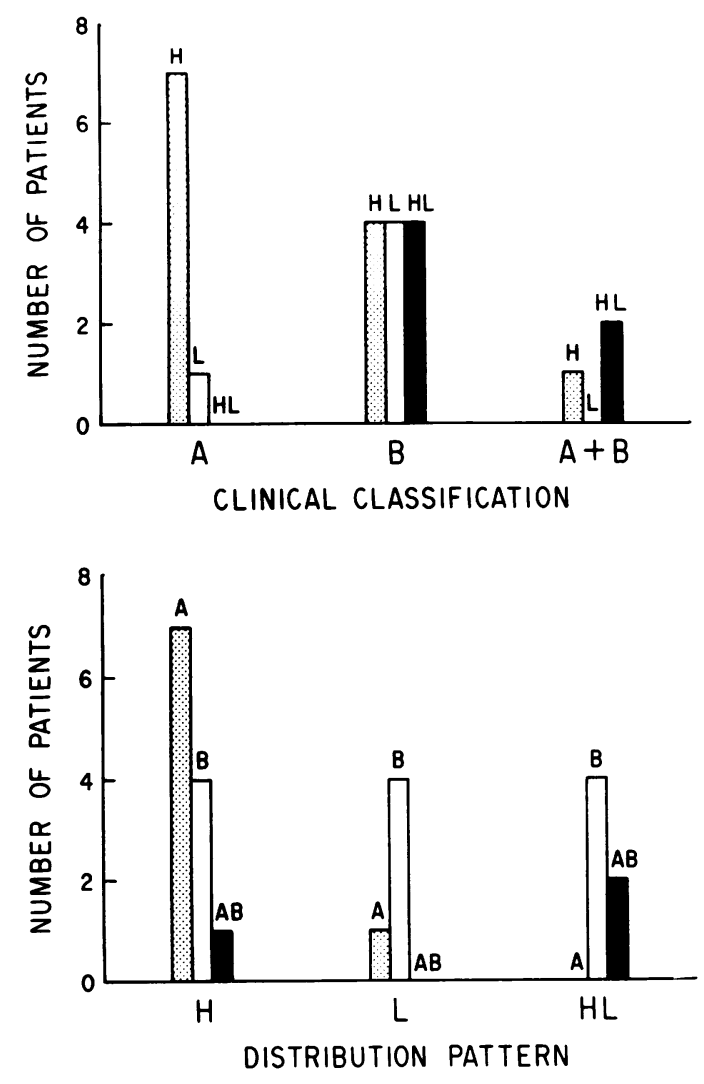

Figure 5 Breakdown of the entire group to show the number of patients of each clinical type with each VA/Q distribution type. Most of the pure type $A$ and mixed type patients had areas of high $\dot{V}_{A} / Q$ (10 of 11). Most, but not all, of the type $B$ and mixed patients had areas of low VंA $Q$ (10 of 15). However, five patients with type $B$ disease had pattern $H$, that is, they did not have low $\dot{V} A / Q$ areas.

study) yields a value for anatomic deadspace of greater than $200 \mathrm{ml}$.

It is therefore reasonable to conclude that the slightly increased amount of minute ventilation 'wasted' on regions of lung with areas of $\dot{V} \mathrm{~A} / Q>100$ is consistent with increases in anatomic deadspace secondary to increases of FRC. Consequently, there do not appear to be quantitatively important areas of lung distal to the conducting airways that are ventilated but not perfused.

\section{Patterns of distribution of $\dot{\mathrm{V}} \mathrm{A} / \mathrm{Q}$ ratios during exercise and while breathing $100 \% \mathrm{O}_{2}$}

Because of their advanced disease, no patients could sustain more than $50 \mathrm{~W}$ of exercise for $10 \mathrm{~min}$ in a steady state, so that $\mathrm{VO}_{2}$ never rose above 1.03 liters/ min. At these limited levels of exercise, there were generally no systematic changes in the measured inert gas values or in the $\dot{V}_{A} / Q$ pattern. Thus those patients with $\mathrm{L}, \mathrm{H}$, or $\mathrm{HL}$ patterns at rest continued to show the same pattern during exercise, with no detectable quantitative alterations. Respiratory and inert gas data during exercise appear in the Appendix (Tables IV, V). ${ }^{2}$

There were also no detectable systematic changes in the inert gas data or the distributions after $30 \mathrm{~min}$ of breathing $100 \% \mathrm{O}_{2}$, except for the small increase in the shunt discussed above. In particular, the distribution pattern $(\mathrm{L}, \mathrm{H}$, or $\mathrm{HL})$ did not change with $\mathrm{O}_{2}$ breathing.

\section{Relationships between inert and respiratory gas exchange}

A technique for predicting gas exchange for oxygen and carbon dioxide from the recovered $\dot{V}_{A} / Q$ distribution was described earlier, the central assumption being that in every gas exchange unit there is complete diffusion equilibration. The purpose of this computation is to test the hypothesis that the observed $\dot{V} A / Q$ inequality (including shunt) accounts for all of the independently observed hypoxemia, and that there is consequently no detectable impairment of diffusion equilibration. Should this be the case, the statistical relationship between measured and predicted arterial $\mathrm{PO}_{2}$ would be one of identity. On the other hand, if diffusion impairment were a significant factor contributing to hypoxemia, the measured arterial $\mathrm{Po}_{2}$ would be systematically lower than that predicted from $\dot{V} A / Q$ inequality and shunt alone. These arguments depend on the known order of magnitude difference between the rates of diffusion equilibration for inert gases (13) on the one hand, and $\mathrm{O}_{2}$ and $\mathrm{CO}_{2}(14,15,16)$ on the other.

\section{ARTERIAL $\mathrm{PO}_{2}$}

Fig. 6 shows the relationship between measured arterial $\mathrm{PO}_{2}$ and that calculated by the above method (predicted). All measurements in all patients are included: breathing air at rest $\left(\mathrm{PO}_{2}<100\right)$, breathing $100 \% \mathrm{O}_{2}$ at rest $\left(\mathrm{PO}_{2}>100\right)$, and breathing air during exercise. The values obtained from 18 measurements on 10 patients during exercise are shown by the open circles. Actual retentions and mixed venous respiratory gas data were obtained under all of these conditions and were used to calculate the arterial $\mathrm{PO}_{2}$.

Breathing room air at rest. Over the range from 36 to $75 \mathrm{~mm} \mathrm{Hg}$, there was good statistical agreement between calculated and measured arterial $\mathrm{PO}_{2}(r=0.95$ and the relationship not different from identity), suggesting that the observed $\dot{V}_{A} / \dot{Q}$ inequality (and shunt, when present) accounted for all of the measured hypoxemia. The increasing scatter with increasing $\mathrm{PO}_{2}$ most likely represents effects of the decreasing slope of the $\mathrm{O}_{2} \mathrm{Hb}$ dissociation curve. $\mathrm{As} \mathrm{PO}_{2}$ rises 


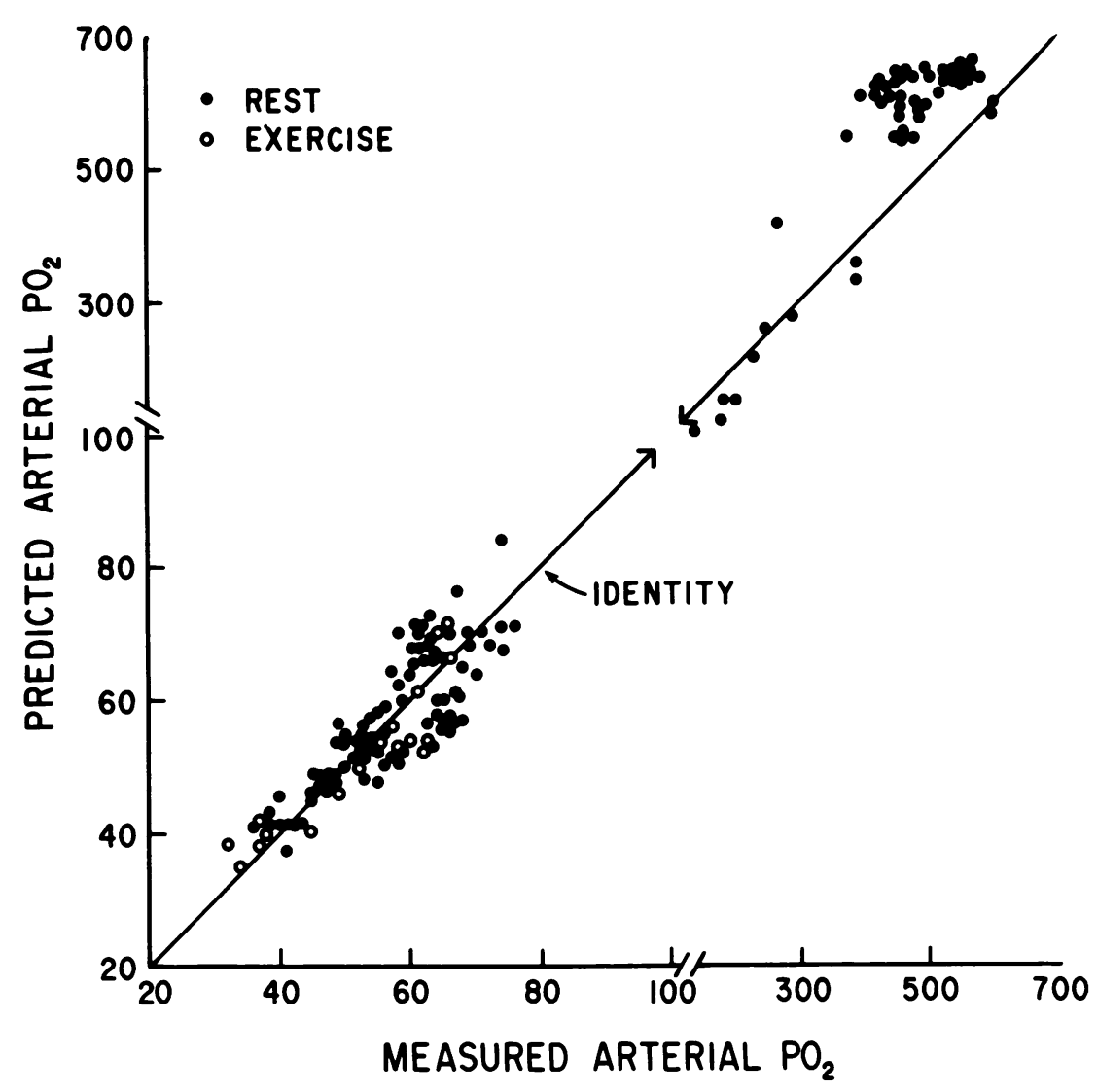

FIGURE 6 Comparison of all individual values of measured arterial $\mathrm{PO}_{2}$ at rest $(\odot)$ and during exercise $(O)$ with corresponding values calculated from the recovered $\dot{V}_{A} / Q$ distributions and shunt. Note the scale change above $100 \mathrm{~mm} \mathrm{Hg}$. Values in Table II are means under each condition. There is good agreement up to $\mathrm{PO}_{2}$ values of $300 \mathrm{~mm} \mathrm{Hg}$, with no systematic variation from the identity relationship. The systematic differences at high $\mathrm{Po}_{2}$ are explained in the text. The results breathing air $\left(\mathrm{PO}_{2}<100\right)$, especially during exercise, suggest that diffusion equilibration of alveolar gas with end-capillary blood is adequate.

this causes a larger error in calculated $\mathrm{PO}_{2}$ for a given error in calculated $\mathrm{O}_{2}$ content. In Fig. 6, at a $\mathrm{PO}_{2}$ of 40 , the scatter is $\pm 4 \mathrm{~mm} \mathrm{Hg}(95 \%)$ while at $\mathrm{PO}_{2}$ of 60 it is $\pm 9 \mathrm{~mm} \mathrm{Hg}$ for $95 \%$ of values. Because of the shape of the $\mathrm{O}_{2} \mathrm{Hb}$ dissociation curve, these both correspond to about $\pm 0.8 \mathrm{ml} \%$ scatter in $\mathrm{O}_{2}$ content. It must be remembered that this scatter reflects the cumulative error of inert gas measurements, of measurements of arterial and venous $\mathrm{PO}_{2}$ and $\mathrm{PCO}_{2}$, and of ancillary variables such as $\mathrm{Hb}$ and $\mathrm{P}_{\mathbf{5 0}}$.

Breathing room air during exercise. Arterial $\mathrm{Po}_{2}$ fell with exercise in every patient, but over the measured range of from 34 to $62 \mathrm{~mm} \mathrm{Hg}$ the agreement between measured and calculated arterial $\mathrm{PO}_{2}$ was equally as good as at rest (Fig. 6).

The predictability of arterial $\mathbf{P O}_{2}$, especially during exercise, supports the hypothesis that failure of alveolar end-capillary diffusion equilibrium is not present as a mechanism contributing to hypoxemia in these patients. Even if individual discrepancies between measured and calculated $\mathrm{Po}_{2}$ in Fig. 6 were the result of diffusion impairment (rather than experimental error), this mechanism must play a minor role in terms of the total alveolar-arterial $\mathrm{PO}_{2}$ difference $\left(\mathrm{AaDO}_{2}\right)$. For example, at a $\mathrm{PO}_{2}$ of $40\left(\mathrm{AaDO}_{2}\right.$ of about $60 \mathrm{~mm} \mathrm{Hg}$ ), the observed maximum difference of $4 \mathrm{mmHg}$ is only $1 / 15$ or about $7 \%$ of the total $\mathrm{AaDo}_{2}$.

While this agreement between measured and calculated $\mathrm{PO}_{2}$ excludes a significant contribution to hypoxemia from failure of alveolar end-capillary diffusion equilibrium, it should not be taken to imply that the rate of capillary $\mathrm{PO}_{2}$ equilibration is necessarily normal. Our conclusion is simply that sufficient time is available to permit equilibration by the end of the red cell capillary transit. It has been established from theoretical calculations $(14,16,17)$ that the overall capillary exchange process (combined diffusion and chemical equilibration) must be retarded by a factor of about four before detectable alveolar end-capillary differences will occur. Thus, considerable reduction in 
diffusing properties of the blood gas barrier could be present and undetectable by this method.

It is concluded on the basis of $(a)$ the agreement between measured and predicted $\mathrm{PO}_{2}$, and $(b)$ the lack of change in the distributions with exercise that the reason for the fall in arterial $\mathrm{Po}_{2}$ during exercise was the fall in mixed venous $\mathrm{PO}_{2}$ which in turn was the result of the relatively greater rise in $\dot{\mathrm{V}}_{2}$ than in cardiac output.

Breathing $100 \% \mathrm{O}_{2}$ at rest. There was good agreement between the measured and calculated arterial $\mathrm{PO}_{2}$ in the two patients with large shunts as determined by the inert gas method $\left(\mathrm{PO}_{2}\right.$ in the range $100-300 \mathrm{~mm} \mathrm{Hg}$ ). On the other hand, in the remaining 21 patients there was usually a large (50-200 $\mathrm{mm} \mathrm{Hg}$ ) difference between the calculated and measured $\mathrm{PO}_{2}$ values during $\mathrm{O}_{2}$ breathing. The measured value was virtually always considerably lower than predicted from the inert gas data (Fig. 6). As stated previously in discussing the same finding in normal subjects (4), it is reasonable to ascribe perhaps 50 $\mathrm{mm} \mathrm{Hg}$ of this discrepancy to the combined effects of bronchial and Thebesian venous admixture (not detected by the inert gas method) and of errors in $\mathrm{Po}_{2}$ measurement at these high values. This, however, leaves residual differences of up to $150 \mathrm{~mm} \mathrm{Hg}$ between calculated and measured $\mathrm{PO}_{2}$.

Since the retention of the inert gases of low solubility was essentially stable for $2 \mathrm{~h}$ during these studies (after the initial 30-min equilibration period), and certainly never increased systematically, it is highly unlikely that the discrepancy results from falsely low retention values for the insoluble gases resulting, in turn, from failure of equilibration within the lungs.

A more reasonable hypothesis for the $\mathrm{Po}_{2}$ discrepancy during $\mathrm{O}_{2}$ breathing is that after $30 \mathrm{~min}$ of $\mathrm{O}_{2}$ breathing, the alveolar $\mathrm{PO}_{2}$ in low $\dot{\mathrm{V}} \mathrm{A} / \mathrm{Q}$, poorly ventilated gas exchange units remained considerably below the predicted steady-state value for complete denitrogenation. Three factors could combine to produce this effect: $(a)$ existence of poorly ventilated low $\dot{V} A / Q$ regions of lung; $(b)$ inevitable small leaks in the $\mathrm{O}_{2}$ delivery system, such that the effective $\mathrm{FiO}_{2}$ was not precisely 1.0 ; and (c) continuing elimination of $\mathrm{N}_{2}$ from the tissues.

\section{ARTerial $\mathrm{PCO}_{2}$ AND MIXED EXPIRED $\mathrm{PO}_{2}$ AND $\mathrm{PCO}_{2}$}

The comparisons between measured and calculated arterial $\mathrm{PCO}_{2}$ and mixed expired $\mathrm{PO}_{2}$ and $\mathrm{PCO}_{2}$ were made but are considerably less informative than that of arterial $\mathrm{PO}_{2}$.

For arterial $\mathrm{PCO}_{2}$, because of the usually small arteriovenous tension difference and the errors of measurement of $\mathrm{PCO}_{2}( \pm 2 \mathrm{~mm} \mathrm{Hg}$ for $95 \%$ limits $)$, the comparison is very insensitive to the nature of the $\dot{V} \mathrm{~A} / \dot{Q}$ distribution. Agreement between measured and predicted $\mathrm{PCO}_{2}$ was good over an almost $60 \mathrm{~mm} \mathrm{Hg}$ range of $\mathrm{PCO}_{2}(23-79)$ with $r=0.98$ and $95 \%$ of the calculated values lying between $\pm 3 \mathrm{~mm} \mathrm{Hg}$ of measured $\mathrm{PCO}_{2}$.

Over a much narrower range $(10-27 \mathrm{~mm} \mathrm{Hg})$ of mixed expired $\mathrm{PCO}_{2}$, there was equally good agreement between calculated and measured $\mathrm{PCO}_{2}$, and similar results were obtained for expired $\mathrm{PO}_{2}$.

\section{Relationships between respiratory gas exchange and the pattern of $\dot{V} A / Q$ distribution}

Those patients with type A COPD generally had well-preserved arterial blood gases since this was one of the criteria for selection. Thus arterial $\mathrm{PO}_{2}$ was only once (patient 7) below $60 \mathrm{~mm} \mathrm{Hg}$, and $\mathrm{PCO}_{2}$ exceeded $45 \mathrm{~mm} \mathrm{Hg}$ only once (patient 2). These patients had sufficient minute ventilation (mean of 11.0 liters/ min) to prevent $\mathrm{CO}_{2}$ retention. They were hypoxemic because the main body of the blood flow distribution was shifted slightly toward low $\dot{V}_{A} / Q$ values. Thus, as Fig. 2 shows, the main body of the distribution in the $\mathrm{H}$ pattern is typically centered on a $\dot{V}_{\mathrm{A}} / \dot{Q}$ of about

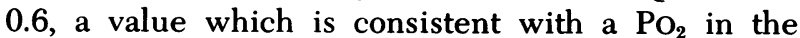
$60-70 \mathrm{~mm} \mathrm{Hg}$ range. By contrast, there was essentially no contribution to hypoxemia in this group from shunt or areas of very low $\dot{V}_{A} / Q(<0.1)$.

It is of interest to compare the blood gases of four patients, of clinical type B (or mixed type) but who had $\dot{V}_{A} / Q$ patterns of the $H$ type (Fig. 2). In two (patients 17 and 23 with minute ventilation of 9.9 and 10.2 liters $/ \mathrm{min}$ ), the positions of the distributions and the arterial $\mathrm{PO}_{2}$ and $\mathrm{PCO}_{2}$ were essentially the same as in the type A patients, but in the remaining two (patients 13 and 16 with minute ventilations of 7.0 and 8.1 liters/min) there was more severe hypoxemia and there was hypercapnia. Fig. 2 can be used to compare these two subgroups of patients with the typical type $\mathrm{H}$ distribution in patients $2-10$. It can be seen that the main body of the distribution is shifted considerably more toward lower $\dot{V} A / Q \dot{Q}$ values in patients 13 and 16.

In other words, the finding that grossly dissimilar blood gases were found in patients with qualitatively similar $\dot{V}_{A} / Q$ patterns is compatible with the relatively lower mean $\dot{V} A / Q$ in the more hypoxemic patients, which in turn is compatible with their reduced minute ventilations, also found by King and Briscoe (2).

This finding is reinforced by examining the patients with the $\mathrm{L}$ type patterns in whom the range of arterial $\mathrm{PO}_{2}$ was $47-71 \mathrm{~mm} \mathrm{Hg}$. In all examples, prediction of $\mathrm{PaO}_{2}$ was good (Fig. 6). The conclusions are that it is often not possible to infer even the broad pattern 
(H, L, HL) of $\dot{\mathrm{V}} \mathrm{A} / \mathrm{Q}$ inequality from the arterial blood gases. Moreover, dissimilar $\dot{V}_{A} / \dot{Q}$ patterns may give rise to similar $\mathrm{PO}_{2}$ and $\mathrm{PCO}_{2}$ values.

\section{DISCUSSION}

Assumptions of steady-state conditions. Studies were not made without evidence of a general cardiopulmonary steady state as indicated by stability of heart rate, tidal volume and frequency, arterial and mixed venous blood gases, end-tidal and mixed expired $\mathrm{PO}_{2}$ and $\mathrm{PCO}_{2}$, and mean pulmonary artery pressure (all to within $\pm 10 \%$ ). Occasionally, tidal volume or frequency changed between duplicate measurements, but when this was observed, $5 \mathrm{~min}$ at the new level of ventilation was allowed before sampling, on the basis of previous studies in dogs (18).

Additional evidence that inert gas exchange was in an acceptable steady state was the agreement for all gases in retention (and excretion) between initial and duplicate values obtained under a given circumstance 5 min apart. In the entire study of 23 patients, 118 such duplicate measurements (i.e., 59 pairs) were obtained. The mean difference was not statistically different from zero for any gas supporting the argument that a sufficiently steady state existed. Further support lies in the mean (of initial and duplicate) values breathing air at rest at the beginning of the study and again about $1 \mathrm{~h}$ later on in the study (either after breathing $100 \% \mathrm{O}_{2}$ or after a period of exercise). In the twenty studies in which two such runs (breathing air at rest) were made, the mean difference $(\Delta)$ in retention (and excretion) individually for each gas was not significantly different from zero (overall $\Delta=0.003, \pm 0.027$ $\mathrm{SD}$ ). For the gas $\mathrm{SF}_{6}$ (most likely to require the longest time to reach a steady state on theoretical grounds [5]) $\Delta=-0.002 \pm 0.011 \mathrm{SD}$ (at a mean $\mathrm{SF}_{6}$ retention of 0.045). This supports the contention that even $S_{6}$ had reached steady-state levels within $30 \mathrm{~min}$ of beginning the infusion.

Assumptions of diffusion equilibrium. The method depends on mass balance and uses the Fick principle, as originally formulated by Farhi (19). Specifically, at the level of the gas exchange unit, this implies complete alveolar end-capillary duffusion equilibrium for the inert gases.

Should this asumption not be justified for the inert gases, there should be a detectable molecular weightdependent behavior of elimination. This was never found. However, by the time such a severe degree of interference to diffusion across the blood-gas barrier existed, there would be a far greater degree of interference for $\mathrm{O}_{2}$, and the inert gas data would not be consistent with the measured arterial $\mathrm{Po}_{2}$. Fig. 6 confirms the consistency of blood gas and inert gas data.

Assumptions of parallel inhomogeneity. It is pos- sible that some of the inequality in COPD may arise from series inequality - a situation in which some gas exchange units inspire (partly or wholly) from other gas exchange units. For these "parasitic" units, inspired gas levels would not be zero. We recently analyzed inert gas exchange in such a system (20) taking into account simultaneous $\mathrm{O}_{2}$ and $\mathrm{CO}_{2}$ exchange, and the results suggest that under the conditions of this study one can always find a 'parallel' lung with identical gas exchange to that in a given 'series' lung.

This finding has two implications: $(a)$ the presence of series inequality will not lead to internal inconsistencies in the analysis so that the parallel formulation will yield an answer that fits the data even if these data come from a 'series' lung; and $(b)$ by the same token it is not possible to separately identify series inequality with the inert gas method (unless as discussed above the series inequality is produced by impaired diffusive gas mixing and is thus molecular weight-dependent).

A further consideration is the effect of reinspiration of deadspace gas. Ross and Farhi (21) showed that because of the sharing of common tracheobronchial pathways the extremes of alveolar gas composition (inspired for ventilated, unperfused areas, and near mixed venous for perfused, essentially unventilated areas) would be unlikely to occur in real lungs as a result of common deadspace reinspiration. Although discussed principally for $\mathrm{O}_{2}$, their arguments also apply to inert gases. While it is presently impossible to assess the quantitative aspects of this phenomenon, the results of the inert gas analysis generally will be to underestimate areas of both high and low $\dot{V}_{\mathrm{A}} / \mathrm{Q}$. Thus the apparent $\dot{V}_{A} / Q$ of a truly high $\dot{V}_{A} / Q$ lung unit reinspiring common deadspace will be lower than expected on the assumption of no common deadspace inspiration.

Relationships of patterns of inequality to clinical type and to pulmonary function. It is clear that virtually all patients possessing type $A$ features demonstrated large amounts of ventilation to lung units with high $\dot{V}_{A} / Q$ ratios, and essentially no shunt or areas of very low $\dot{V}_{A} / Q(<0.1)$ if they were also devoid of type $B$ features. However, such a good correlation was notably absent for the type $B$ patients. One-third each of the type B patients had $\dot{V}_{A} / Q$ patterns $H, L$, and HL (Fig. 1). Moreover, as was pointed out, of the four type B patients with pattern $\mathrm{H}$, two had well preserved blood gases $\left(\mathrm{PO}_{2} \geq 60, \mathrm{PCO}_{2} \approx 40 \mathrm{~mm} \mathrm{Hg}\right)$, while two had severe hypoxemia with $\mathrm{CO}_{2}$ retention $\left(\mathrm{PO}_{2}<50\right.$, $\left.\mathrm{PCO}_{2}>60\right)$. The differences in the distributions were consistent with the differences in blood gases but the shapes of the $\dot{V}_{A} / Q$ patterns were similar. The difference in the distribution was only one of position along the $\dot{V}_{\mathrm{A}} / Q$ axis, presumably related to the lower alveolar ventilation in the two more hypoxemic 
A

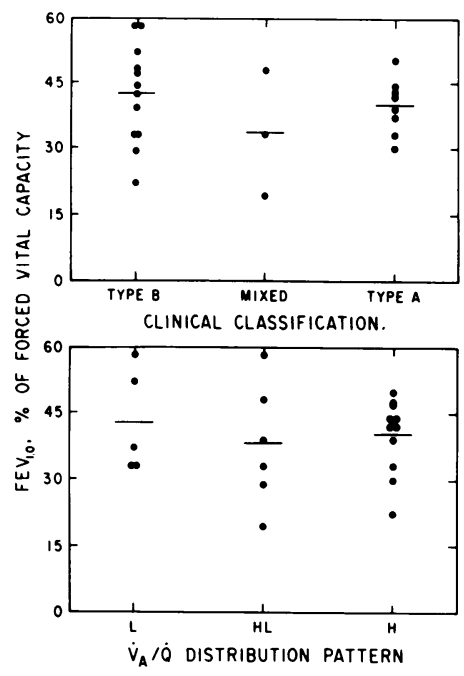

C

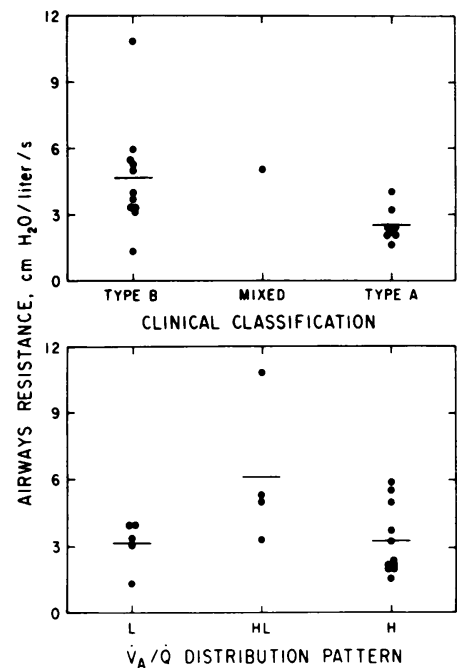

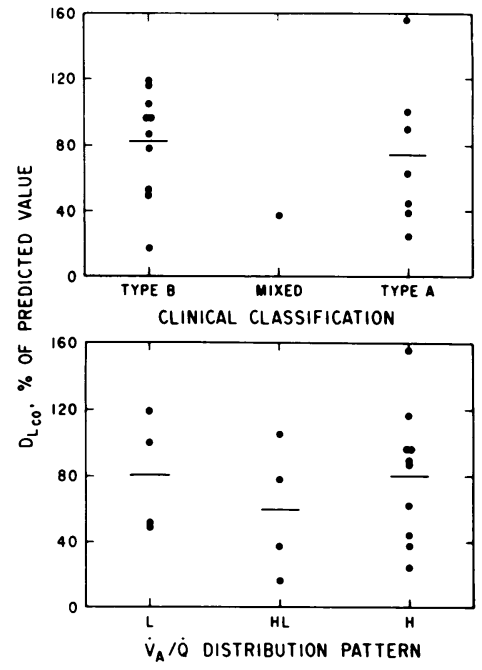

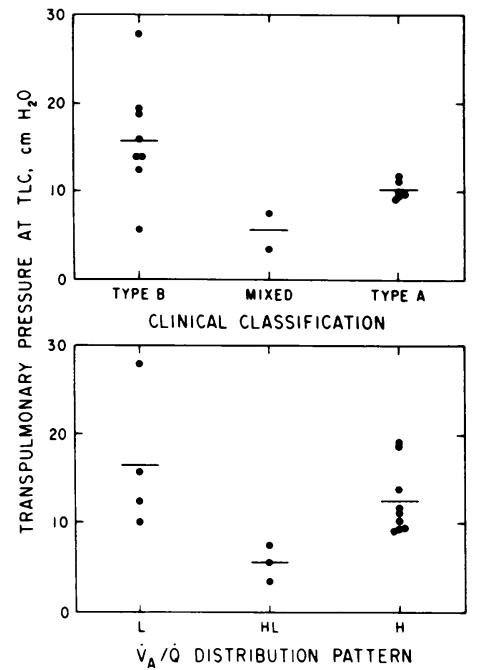

FIgURE 7 Individual values for four basic physiological indices of pulmonary function. Values are given both with respect to clinical type $\left(\mathrm{A}, \mathrm{B}\right.$, mixed) and $\dot{\mathrm{V}}_{\mathrm{A}} / \dot{Q}$ pattern $(H, L, H L)$. We are unable to detect any relationship between any of these tests and the pattern of distribution with the possible exception referred to earlier of the frequent association between increased compliance and the occurrence of high $\dot{V}_{A} / Q$ areas.

patients. Thus, neither purely clinical features nor arterial blood gases were closely related to the $\dot{V} \mathrm{~A} / \dot{Q}$ pattern, although tendencies were observed.

Fig. 7 shows the relationships among $\mathrm{FEV}_{1} / \mathrm{VC} \%$ (A), $\mathrm{DL}_{\mathrm{Co}}(\mathrm{B})$, airways resistance $(\mathrm{C})$, and transpulmonary pressure at total lung capacity (D), and both $\dot{\mathrm{V}}_{\mathrm{A}} / \dot{Q}$ pattern and clinical type. Although in general reduced transpulmonary pressure at total lung capacity (increased compliance) was observed in patients with the $H$ pattern, there were instances of pattern $H$ in the presence of normal transpulmonary pressure values and of absence of pattern $\mathrm{H}$ in the presence of reduced transpulmonary pressure values. There is a reasonable pathophysiological basis for such a relationship (see below), but it is difficult to explain the exceptions noted above.

The degree of airways obstruction as expressed by $\mathrm{FEV}_{1} / \mathrm{VC} \%$ (and by other indices) was also unrelated to the pattern of $\dot{V}_{A} / Q$ inequality. The same lack of relationship held for $\mathrm{DL}_{\mathrm{Co}}$ (single breath).

Anatomical interpretation of $\dot{V} A / Q$ patterns. The production of areas of high $\dot{V}_{A} / Q$ as seen in the $H$ pattern of inequality must involve reduction in blood flow to areas of the lung, since in order to achieve such 
high $\dot{V}_{A} / Q$ ratios without loss of perfusion an enormous fraction of ventilation would have to be directed to an extremely small region of lung. (For example, an area normally receiving just $5 \%$ of the total blood flow and occupying a similar proportion of lung volume would have to receive on the order of half of the total ventilation to achieve a $\dot{V} A / Q$ of 10 . This is unreasonable.)

Such reduction in local perfusion is compatible with the loss of alveolar tissue (and consequently of elastic recoil) seen in emphysema, and may be the important factor in generation of the high $\dot{V} \mathrm{~A} / \dot{Q}$ areas seen in this study. However, it is clear that such a redistribution of perfusion is insufficient to explain all the gas exchange abnormalities, and other reports of delayed nitrogen washout in particular. Irrespective of the method of analysis, nitrogen washout in advanced COPD is grossly abnormal and must represent inequality of ventilation with respect to lung volume (22). Thus the large amount of high $\dot{V}_{A} / Q$ ratio lung observed probably reflects ventilation inequality together with reduction in blood flow.

A similar argument can be applied to the $\dot{V} A / Q$ patterns in which considerable amounts of very low $\dot{\mathrm{V}}_{\mathrm{A}} / \mathrm{Q}$ are found (pattern $\mathrm{L}$ ). Here, there must be reduction in ventilation as the predominant cause of low $\dot{V} A / Q$ ratios rather than an increase in blood flow. (If anything, perfusion is likely to be reduced as a consequence of long-standing hypoxic vasoconstriction in these areas). Such a reduction in ventilation would be consistent with mechanical bronchial obstruction due to mucus, edema, and distortion of airways, and is to be expected in the presence of chronic bronchitis. Such low $\dot{V}_{A} / Q$ areas were, however, seen in only 10 of the 15 patients classified as type $B$ or as mixed types $A$ and $\mathrm{B}$, leaving 5 patients with clinical evidence of chronic bronchitis and no areas of very low $\dot{V}_{A} / \dot{Q}$ ratio.

An additional possible mechanism for these low $\dot{\mathrm{V}} \mathrm{A} / \mathrm{Q}$ areas is suggested by the failure of a shunt to develop after $100 \% \mathrm{O}_{2}$ breathing. Such a shunt frequently develops in patients (and dogs) with abnormal lungs having low $\dot{V} A / Q$ areas after they are given $\mathrm{O}_{2}$ to breathe. The fact that these patients with COPD do not follow this pattern suggests that a different mechanism is responsible, namely, collateral ventilation behind airways that are completely obstructed. In this instance, the low $\dot{V}_{A} / Q$ would in effect be caused by series inequality and preliminary calculations show that under these circumstances, collapse during $\mathrm{O}_{2}$ breathing is much less likely. However, direct evidence for or against this remains to be collected.

\section{ACKNOWLEDGMENTS}

We wish to thank many individuals who made this study feasible. Dr. Gennaro Tisi of the Veterans Administration Hospital, La Jolla, Calif., Dr. John Evans of the Department of Mathematics, University of California, San Diego, Calif., and Peter Naumann and William Tomlin for their technical assistance.

This study was supported by Research Career Development Award HL 00111, National Institutes of Health grants HL 17731-01 and HL 05931-04, and National Aeronautics and Space Administration grant NGL 05-009-109.

\section{REFERENCES}

1. Bates, D. V. 1952. The uptake of carbon monoxide in health and in emphysema. Clin. Sci. (Oxf.) 11: 21-32.

2. King, T. K. C., and W. A. Briscoe. 1968. The distribution of ventilation, perfusion, lung volume and transfer factor (diffusing capacity) in patients with obstructive lung disease. Clin. Sci. (Oxf.) 35: 153-170.

3. Burrows, B., C. M. Fletcher, B. E. Heard, N. L. Jones, and J. S. Wootliff. 1966. The emphysematous and bronchial types of chronic airways obstruction. A clinicopathological study of patients in London and Chicago. Lancet 1: 830-835.

4. Wagner, P. D., R. B. Laravuso, R. R. Uhl, and J. B. West. 1974. Continuous distributions of ventilation-perfusion ratios in normal subjects breathing air and $100 \% \mathrm{O}_{2} . J$. Clin. Invest. 54: 54-68.

5. Wagner, P. D., H. A. Saltzman, and J. B. West. 1974. Measurement of continuous distributions of ventilation-perfusion ratios: theory. J. Appl. Physiol. 36: 588-599.

6. Wagner, P. D., P. F. Naumann, and R. B. Laravuso. 1974. Simultaneous measurement of eight foreign gases in blood gas chromatography. J. Appl. Physiol. 36: 600-605.

7. Wagner, P. D., J. W. Evans, and J. B. West. 1975. Analytically derived distributions of ventilation-perfusion ratios in chronic lung diseases. Fed. Proc. 34: 451. (Abstr.)

8. West, J. B. 1969. Ventilation-perfusion inequality and overall gas exchange in computer models of the lung. Respir. Physiol. 7: 88-110.

9. West, J. B., P. D. Wagner, and C. M. W. Derks, 1974. Gas exchange in distributions of $\dot{V}_{A} / Q$ ratios: the partial pressure-solubility diagram. J. Appl. Physiol. 37: 533-540.

10. Dantzker, D. R., P. D. Wagner, and J. B. West. 1975. Instability of lung units with low $\dot{V}_{A} / Q$ ratios during $\mathrm{O}_{2}$ breathing. J. Appl. Physiol. 38: 886-895.

11. Wagner, P. D., D. R. Dantzker, R. Dueck, R. R. Uhl, R. Virgilio, and J. B. West. 1974. Continuous distributions of ventilation-perfusion ratios in acute and chronic lung disease. Clin. Res. 22: 134A. (Abstr.)

12. Hart, M. C., M. M. Orzalesi, and C. D. Cook. 1963. Relation between anatomic respiratory dead space and body size and lung volume. J. Appl. Physiol. 18: 519-522.

13. Forster, R. E. 1964. Diffusion of gases. Handb. Physiol. 1(Sect. 3): 839-872.

14. Staub, N. C. 1963. Alveolar-arterial oxygen tension gradient due to diffusion. J. Appl. Physiol. 18: 673-680.

15. Visser, B. F., and A. H. Maas. 1959. Pulmonary diffusion of oxygen. Phys. Med. Biol. 3: 264-272.

16. Hill, E. P., G. G. Power, and L. D. Longo. 1973. Mathematical simulation of $\mathrm{O}_{2}$ and $\mathrm{CO}_{2}$ exchange. Am. J. Physiol. 224: 904-917.

17. Wagner, P. D., and J. B. West. 1972. Effects of diffusion impairment on $\mathrm{O}_{2}$ and $\mathrm{CO}_{2}$ time courses in pulmonary capillaries. J. Appl. Physiol. 33: 62-71.

18. Wagner, P. D., R. B. Laravuso, E. Goldzimmer, P. F. Naumann, and J. B. West. 1975. Distributions of ventilation-perfusion ratios in dogs with normal and abnormal lungs. J. Appl. Physiol. 38: 1099-1109. 
19. Farhi, L. E. 1967. Elimination of inert gas by the lung. Respir. Physiol. 3: 1-11.

20. Wagner, P. D., and J. W. Evans. 1975. Comparison of inert gas exchange in series and parallel models of the lung. Physiologist. 435. (Abstr.)

21. Ross, B. B., and L. E. Farhi, 1960. Dead-space ventilation as a determinant in the ventilation-perfusion concept. J. Appl. Physiol. 15: 363-371.

22. Briscoe, W. A., E. M. Cree, S. Filler, H. E. J. Houssay, and A. Cournand. 1960. Lung volume, alveolar ventilation and perfusion interrelationships in chronic pulmonary emphysema. J. Appl. Physiol. 15: 785-795.

23. Olszowka, A. J. 1975. Can VA/Q் distributions in the lung be recovered from inert gas retention data. Respir. Physiol. 25: 191-198.

24. Evans, J. W., and P. D. Wagner. 1976. Limits on VA/Q́ distributions from analysis of experimental inert gas elimination. J. Appl. Physiol. In press.

25. Wagner, P. D. 1976. A general approach to the evaluation of ventilation-perfusion ratios in normal and abnormal lungs. Physiologist. In press.

26. Dantzig, G. B. 1963. Linear Programming and Extension. Princeton, Univeristy Press, Princeton, N. J. 94-108.

27. Lawson, C. L., and R. J. Hanson. 1974. Solving Least Squares Problems. New Jersey: Prentice-Hall Inc., Englewood Cliffs, N. J. 160-164, 190. 